\title{
O trabalho artesanal: cultura e pertencimento ao local
}

\author{
The artisanal work: culture and local belonging
}

\author{
Jessica Gislaine das Neves ${ }^{1}$ \\ Mayra Taiza Sulzbach ${ }^{2}$
}

\begin{abstract}
Resumo
O presente trabalho é um ensaio teórico que apresenta aproximações das linhas de pesquisas das autoras com as temáticas da disciplina de Configurações produtivas de base coletiva, solidária e sustentável do Programa de Pós-Graduação em Desenvolvimento Territorial Sustentável da UFPR Setor Litoral. Para a elaboração deste trabalho foram utilizadas leituras aprofundadas dos textos da disciplina e anotações a partir dos debates em sala de aula. Este trabalho objetiva promover o debate sobre cultura e economia a partir do trabalho artesanal. $O$ trabalho inicia com algumas concepções históricas de trabalho e segue com a especificidade do trabalho artesanal (conceito, características, permanência). O trabalho artesanal é observado pela ótica da cultura, pelo saber-fazer, característico de cada território e capaz de promover pertencimento ao território (ZAOUAL, 2006). O trabalho artesanal também é observado pela ótica da economia, por ser ele promotor de subsistência específica de cada território, ou seja, possibilitando observar outra economia.
\end{abstract}

Palavras-chave: Saberes. Trabalho. Socioeconomia. Sítios simbólicos. Desenvolvimento territorial sustentável.

\begin{abstract}
The present project is a theoretical essay that presents approximations of the research lines of the authors with the themes of the Collective-based Productive Configurations, Solidary and Sustainable subject of the Post-Graduation Program in Sustainable Territorial Development UFPR Coast Branch. For the elaboration of this work we used in-depth readings of the texts of the subject and notes made during the debates in the classroom. This work aims to promote the debate about culture and economy from the artisanal work. The project begins with some historical conceptions of work and follows with the specificity of the artisanal work (concept, characteristics, permanence). Artisanal work is observed from the point of view of culture, from the know-how, which is a characteristic of each territory and capable of promoting belonging to that territory (ZAOUAL, 2006). Artisanal work is also observed from the point of view of the economy, as it is a promoter of subsistence, specific to each territory, that being, making it possible to observe another economy.
\end{abstract}

Keywords: Knowledges. Work. Socioeconomics. Symbolic places. Sustainable territorial development.

\footnotetext{
${ }^{1}$ Geógrafa (UEPG). Mestranda do Programa de Pós-Graduação em Desenvolvimento Territorial Sustentável (PPGDTS) da Universidade Federal do Paraná. E-mail: jegislaineneves@ gmail.com

${ }^{2}$ Doutora em Desenvolvimento Econômico (UFPR). Professora dos Programas de Pós-Graduação em Desenvolvimento Territorial Sustentável (PPGDTS) e Desenvolvimento e Meio Ambiente (PPGMADE) da UFPR. E-mail: mayrasulzbach@yahoo.com.br
} 


\section{Introdução}

O trabalho artesanal é uma prática que permanece viva em diversas partes do mundo, mesmo após a globalização do modelo de produção em massa. A adjetivação "artesanal” no termo trabalho conduz a refletir sobre as diferentes dimensões que esse abrange: cultural, econômica, social e territorial. A dimensão cultural chama atenção quando se observam diferentes formas de organização da produção, a exemplo da organização do trabalho artesanal e da organização do trabalho à produção industrial. A organização do trabalho não é uma simples busca ao aumento da produtividade humana; ela é resultado da organização social da propriedade dos meios e dos instrumentos de distribuição da produção, organização, que podem impor a privação das liberdades humanas, inclusive a de subsistência.

Este artigo decorre dos resultados das pesquisas bibliográficas, do ensino na disciplina Socioeconomia e saberes locais do Programa de Pós-Graduação em Desenvolvimento Territorial Sustentável da Universidade Federal do Paraná (PPGDTS/UFPR) e das práticas extensionistas das autoras. O produto do trabalho artesanal no Brasil é observado em feiras de rua e se processam através de organizações associativas ou cooperativas quando os espaços de venda ou de produção são comuns aos artesãos, subsistindo ao produto das organizações produtivas privadas mercantis capitalistas e da falta de políticas públicas de apoio pelo Estado. O produto artesanal é derivado do trabalho humano de um indivíduo que detém o saber-fazer, diferentemente do produto industrial, derivado da divisão do saber que exige a organização social para a efetivação. Assim, o produto artesanal surge, na contemporaneidade, como uma alternativa de organização ao trabalho, restaurando o modo de viver específico dos territórios, num movimento contra-hegemônico da propriedade privada dos meios de produção, inclusive da propriedade do homem como mercadoria. O modo de vida, desenvolvido na prática do produto artesanal, também rompe com o aumento do poder concedido ao Estado na regulação dos meios de subsistência.

O trabalho artesanal é uma prática que emerge de outros saberes, que não os dos conhecimentos científicos modernos, os quais fazem parte do pacote hegemônico, das mercadorias privadas das sociedades contemporâneas. O trabalho artesanal é derivado da tradição, sem custo monetário, é derivado de saberes repassados de geração em geração, limitado pelo tempo e espaço do homem como elemento da natureza, fazendo parte da cultura, dos territórios. A organização da produção, por sua vez do trabalho, é tema central da obra de Zaoual (2006), o qual nos apoia numa reflexão sobre o homem situado, o qual é um homem que estrutura sua sociedade para sustentação desta ao longo do tempo, um homem que detém modos de vida que respeitam saberes, ferramentas e natureza do lugar, logo, uma sociedade que a partir da organização do trabalho promove 
sustentabilidades. Zaoual (2006) justifica que o conhecimento científico foi o grande promotor do modelo de desenvolvimento industrial, o qual se coloca como homogêneo à participação do global. Se a racionalidade individual, que promoveu a perda de identidade do homem como elemento da natureza, ampliando sua capacidade de destruí-la e sua posse de dinheiro à ampliação do consumo individual é decorrente dos conhecimentos científicos e da divisão do trabalho à produção industrial, outras racionalidades estão presentes no trabalho artesanal e nas organizações decorrentes desse, clamando por investigações. No viés da existência de outras racionalidades, Polanyi (2000) contribui teoricamente com a defesa de outras economias, outros princípios que movem as organizações humanas.

Convidando-os às reflexões, este artigo inicia apresentando diferentes concepções de trabalho, sendo que uma delas permite compreender o trabalho artesanal como uma definição no tempo e no espaço, um saber-fazer transferido de geração em geração, uma tradição cultural, ou seja, um modo de vida de uma sociedade específica. Posteriormente, aborda-se a teoria dos sítios simbólicos de pertencimento de Zaoual (2006), a qual se baseia na identidade territorial do homem situado, e a teoria da economia substantiva de Polanyi (2000), que apresenta princípios que movem a troca entre os homens. $\mathrm{O}$ trabalho não termina, apenas expõe algumas breves considerações gerais sobre o discutido.

\section{Notas históricas do trabalho}

Compreender o trabalho e suas organizações sociais tem sido fundamental para resolução dos problemas complexos das sociedades, exigindo que as definições que o trabalho recebeu na sociedade sejam explanadas, pois essas definições correspondem a como as sociedades materializavam-se por meio de suas significações. A história é outro instrumento que apoia no sentido de observar os diferentes significados que as palavras carregam. E assim procedemos para compreender os diferentes significados de trabalho para posterior adentrar ao trabalho artesanal. O Dicionário Michaelis (2018), apresenta diversas definições sobre trabalho, algumas delas são:

1 Conjunto de atividades produtivas ou intelectuais exercidas pelo homem para gerar uma utilidade e alcançar determinado fim [...] 2 Atividade profissional, regular, remunerada ou assalariada, objeto de um contrato trabalhista [...] $3 \mathrm{O}$ exercício dessa atividade [...] 4 Local onde se exerce essa atividade [...] 5 Qualquer obra (manual, artística, intelectual) realizada; empreendimento, realização [...] $6 \mathrm{~A}$ feitura ou execução de uma obra; lavor [...] 7 Ação ou maneira de executar uma tarefa, de utilizar um instrumento: Seu trabalho com nanquim é perfeito. 8 Tarefa a ser cumprida; serviço [...] 9 Esmero ou cuidado empregado na feitura de uma obra 
ou de um [...]. 10 Qualquer tarefa que é ou se tornou uma obrigação ou responsabilidade de alguém; dever, encargo.

Já trabalho, no Dicionário Etimológico (2017), de acesso restrito, vem do latim tripalium, constituída da junção de tri, que significa "três" e palum, que significa "madeira". "Tripalium era o nome de um instrumento de tortura constituído de três estacas de madeira bastante afiadas.” Essa significação da palavra remete ao Século VI, início da Idade Média, período em que as pessoas eram sujeitas a tortura pelo império Romano.

Na história da humanidade, o trabalho foi, ou ainda é, resposta para o atendimento das necessidades humanas. Historicamente (tempo/espaço), o trabalho recebeu diferentes significações: meio de subsistência, forma de submissão, manifestação de força, distinção de posse, entre outras. O ser humano, o qual realiza o trabalho, também foi denominado/percebido de diferentes maneiras ao longo da história: artesão, escravo, empregado, improdutivo, entre outras.

O trabalho na pré-história da humanidade foi caracterizado por práticas nômades de subsistência, atendendo assim ao sentido de subsistência humana. De acordo com a cartilha da Incubadora Tecnológica de Cooperativas Populares de Itajubá - INTECOOP (2017, p. 8), os homens "caçavam, pescavam, colhiam e dividiam os alimentos entre sua própria tribo (caracterizando uma produção de subsistência). Desta forma só produziam aquilo que poderiam consumir".

No decorrer da história das sociedades dos homens, as construções coletivas se voltaram em torno: do econômico, do social, do político, do território, da natureza e do próprio homem, desenvolvendo sistemas produtivos e distributivos, mas que não retiraram a centralidade do trabalho como forma de promoção da subsistência humana nas sociedades: escravocrata, feudal, capitalista, estatal etc.

As inovações tecnológicas das sociedades ocidentais transformaram outras que acompanharam os paradigmas tecnológicos que orientaram a estruturação de organização do trabalho industrial. Como argumenta Castells (1999, p. 50): “a nova sociedade que emerge desse processo de transformação é capitalista e também informacional, embora apresente variação histórica considerável nos diferentes países". Mesmo com a internacionalização tecnológica, sobrevivem práticas dos tradicionais de organizar a produção e distribuição, ou ainda, práticas de trabalho que promoveram e promovem a subsistência humana.

Se não bastassem as tecnologias, que reduziam os esforços físicos do homem, as instituições internacionais, como o Banco Mundial e o Fundo Monetário Internacional, também contribuíram para a mudança nas formas de organização da produção e hábitos de consumo. As 
inovações tecnológicas trouxeram a dependência de fatores energéticos, como o petróleo, e dos países não produtores desse, resultando em inflação, endividamento interno e externo. Países com esses sintomas foram acompanhados por décadas pelas instituições internacionais para a solução dos problemas, os quais deveriam seguir o pacote de instruções: as formas de organização social, econômica, enfim, cultural, inclusive a organização do trabalho, contrapondo ou ameaçando, dessa maneira, o trabalho artesanal.

No Brasil, a modernização no campo que ocorreu com a mecanização e o uso de sementes geneticamente modificadas e de agrotóxicos promoveu mudanças na organização do trabalho no campo, que antes era artesanal, realizado, prioritariamente, pela agricultura familiar. Junto com a modernização, alteraram-se: a natureza, os hábitos alimentares, a estrutura familiar, entre outros. A biodiversidade do solo, do ar e da água é trocada pela monocultura; a diversidade de alimentos é trocada pela monocultura, a estrutura familiar é substituída pela racionalidade econômica. Nesse mesmo Brasil, a hegemonia da modernização agrícola não foi alcançada como se propunha, seja pela resiliência das práticas da agricultura familiar, seja por incompatibilidades naturais (relevo, solo ou clima local). Lugares que passaram a ser denominados de subdesenvolvidos, não cabendo aqui essa discussão, cabendo apenas destacar que, o desenvolvimento, nesse contexto, é derivado da homogeneização do modo de produção industrial, ou seja, da organização do trabalho que passou a predominar.

O que se pode concluir a partir da diferença é que do trabalho artesanal, para a subsistência, e da organização do trabalho para a produção em massa, são que os fins justificam os meios, e esses têm diferentes sentidos, ou seja, o trabalho recebe diferentes significados, com base no tempo e no espaço, mas sem perder a centralidade na organização das sociedades. O trabalho artesanal, que promoveu a subsistência do homem, é ainda reproduzido nas sociedades contemporâneas, podendo ser observado como uma organização social que recoloca o homem como elemento da natureza, ensinando outras racionalidades que o homem econômico (da produção industrial) deixou ou vem deixando de processá-las.

\section{O trabalho artesanal: um saber tradicional materializado}

O trabalho artesanal, segundo Keller (2011, p. 33), é aquele que prioriza o "fazer humano (fazer manual), em que o uso de ferramentas e instrumentos de trabalho no manuseio da matéria-prima (objeto de trabalho) é subsidiário à vontade do criador”. O trabalho artesanal, segundo o autor, faz uso de recursos locais e não utiliza mecanização de alto porte para a elaboração 
do produto final. Além disso, o trabalho artesanal, geralmente, carrega saberes tradicionais transferidos pelos artesãos na família ou em grupos próximos.

Trabalho e produção artesanal: o trabalho artesanal surge como tema importante em razão de ser uma atividade considerada tradicional e ao mesmo tempo presente na sociedade contemporânea. Trata-se de um trabalho que tem tanto uma dimensão criativa e simbólica quanto econômica e mercantil (KELLER, 2011, p. 31).

O trabalho artesanal se mostra em contraposição ao trabalho moderno, porém, ele é também contemporâneo. O que diferencia o artesanal do moderno é a forma de transmissão do conhecimento, já que o primeiro não é repassado na educação escolar ou educação tecnológica, regulado pela ciência ocidental. A tradição é implícita no trabalho artesanal. E esta tradição não significa paralisia, a tradição também se atualiza, ressignificando-se, mas sem perder a essência de continuidade histórica.

Não impede as inovações e pode mudar até certo ponto, embora evidentemente seja tolhido pela exigência de que deve parecer compatível ou idêntico ao precedente. Sua função é dar a qualquer mudança desejada (ou resistência à inovação) a sanção do precedente, continuidade histórica e direitos naturais conforme o expresso na história (HOBSBAWM; RANGER, 2008, p. 8-9).

O trabalho artesanal une o saber, que pode ser tradicional, conduzido pelas gerações ou pelo local, e o fazer, que pode ser organizado de forma individual ou coletivamente. $\mathrm{O}$ trabalhador artesanal tem o saber de todo o processo de desenvolvimento do produto, desde sua criação. No modo de organização da produção industrial, o processo de produção é fragmentado, o trabalhador só detém o conhecimento da fração a qual ele é designado. Nesse sentido, segundo Keller (2011, p. 32) “os artesãos contemporâneos tornam-se - em diversas situações - uma espécie de guardiões de conhecimentos relativos a processos de produção tradicionais no Brasil e em outras partes do mundo".

O trabalho artesanal, comparativamente a outras formas de organização do trabalho para a produção e distribuição do produto, é pouco pesquisado, e as conclusões dessas são semelhantes:

Os estudos do antropólogo Ricardo Gomes Lima do Museu do Folclore (Centro Nacional de Folclore e Cultura Popular/MinC) sobre o artesanato constituem uma referência teórica importante e fonte para diversas reflexões teóricas quando o tema é o artesanato. Em sua perspectiva, os artesãos são produtores tanto de objetos quanto de cultura (KELLER, 2011, p. 33).

Os "saberes" e os "fazeres" do trabalho artesanal, tradicional, familiar ou do local, desenvolvidos de maneira dialogada com os recursos locais, aparecem ameaçados por interesses 
hegemônicos econômicos, isso porque, apesar da pouca valorização do ofício do artesão, o produto do trabalho é valorizado pelo diferente no meio do competitivo.

O produto artesanal é diferenciado pela carga cultural e pela identidade societária que carrega, ou, em uma linguagem estritamente econômica, um produto com um valor agregado [...] o produto artesanal ganha destaque em uma sociedade de mercadorias globalizadas e padronizadas (KELLER, 2011, p. 32).

O produto do trabalho artesanal, segundo Keller (2011, p. 33), diferencia-se dos produzidos na organização industrial porque "trata-se de um produto diferenciado pela sua dimensão econômica e cultural. Um produto que integra um sistema de valores culturais da comunidade ou região".

O saber-fazer do produto do trabalho artesanal, que é compartilhado e carregado de geração em geração, se reproduz pelas especificidades do território à ativação. Os saberes são recursos que resultam, segundo Benko e Pecqueur (2001, p. 46), "de uma história longa, de uma acumulação de memória, de uma aprendizagem coletiva cognitiva", implícitos nos processos de criação que podem ser individual ou coletivo, respeitando as temporalidades dos envolvidos, e na destinação dos produtos que podem ser para a troca ou comercialização.

O percurso do trabalho artesanal à subsistência, e do trabalho artesanal à comercialização, demonstra a importância do saber-fazer transmitido de geração em geração e da natureza dos lugares. Apesar do produto do trabalho artesanal perder espaço na comercialização, quando observado sob a competitividade do trabalho industrial (produtividade), e ganhar espaço na comercialização, quando observado sob a competitividade do trabalho contemporâneo (diferencial), o trabalho artesanal, o qual dá origem ao produto, é cultural, ou seja, está implícito a um local ou a um ambiente. O que nos remete a observar o valor do trabalho artesanal no local.

\section{Trabalho artesanal: um saber ao pertencimento}

Para Claval (2007, p. 124), a cultura comporta conhecimentos de know-how (saber como) e de saberes de tradição que valorizam o ambiente: "o viés ecológico e econômico da cultura comporta o know-how e os saberes mobilizados para valorizar o ambiente" (CLAVAL, 2007, p. 124).

Numa linha de valorização dos territórios, Zaoual (2006) defende que o pertencimento ao território pode apoiar o desenvolvimento local, sem que esse seja dado pelo viés do desenvolvimento com o sinônimo de crescimento. Para o autor, os indivíduos do local estabelecem 
relação com seus recursos, pelo reconhecimento das especificidades desses, criando um valor simbólico de pertencimento; criando um sítio simbólico de pertencimento do território (local):

De acordo com a orientação da abordagem de sítios [...] expressa a variedade simbólica das situações vividas e dos percursos. O pensamento dos sítios associa os mundos simbólicos e morais dos homens a suas práticas cotidianas. São relações geralmente ocultas que a noção de homo situs redescobre: o homem concreto em seu espaço vivido, isto é, em seu sítio simbólico (ZAOUAL, 2006, p. 31).

Como exposto pelo autor, o pertencimento ao lugar é concebido a partir das situações vividas, dos saberes e das experiências no lugar. Os sítios simbólicos são então concebidos pelos indivíduos por possuírem: uma caixa-preta repleta de imaterialidade, como mitos, valores, sentimentos, contos, sabedorias e crenças; uma caixa conceitual repleta de experiências, vivências, saberes apreendidos, conceitos de vida; e uma caixa de ferramentas que contém os saberes dos fazeres, as técnicas e os modelos de ação próprios ao contexto. A caixa-preta e a caixa conceitual compreendem o indivíduo situado pela materialidade e imaterialidade do local, decorrentes das experiências individuais/coletivas e das abstrações que fazem os indivíduos agirem, e tornarem-se atores da situação: "os atores em dada situação operam com uma caixa de ferramentas que contém o saber-fazer, técnicas e modelos de ação próprios ao contexto" (ZAOUAL, 2006, p. 32).

Os sítios simbólicos:

Impregnam o conjunto das dimensões dos territórios de vida: relação ao tempo, à natureza, ao espaço, ao habitat, à arquitetura, ao vestuário, às técnicas, ao saber fazer, ao dinheiro, ao empreendedorismo etc. Antes de se materializar nos efeitos e gestos dos atores ou em qualquer outra materialidade visível a olho nu, os sítios são entidades imateriais fornecedoras de balizamento para os indivíduos e suas organizações sociais (ZAOUAL, 2006, p. 34).

São nos sítios simbólicos que o trabalho artesanal encontra espaço para desenvolver-se e desenvolver o local. O saber-fazer do trabalho artesanal compreende a materialidade e imaterialidade de símbolos de um local, o que justifica ele propagar-se nas gerações, reduzindo as incertezas externas, as quais, segundo Zaoual (2006), estão sujeitas as organizações. O trabalho artesanal materializa as abstrações do território, sendo o homem situado a maior materialização.

Zaoual (2006) e igualmente Keller (2011) argumentam que a tradição não é estática ou limitada ao passado. Os sítios recebem influências e são moldados constantemente, configurando-se em tradições sustentadas, que podem fornecer estabilidades aos fenômenos sociais. O saber-fazer inerente ao trabalho artesanal é num território construído (PECQUEUR, 2005), o qual traz representações simbólicas e imaginativas dos indivíduos de um local. 
As sociedades não são feitas apenas de trocas calculáveis e não calculáveis, mas também de enraizamentos e de valores não intercambiáveis. Numerosos estudos econômicos, sociológicos ou antropológicos evidenciam o necessário enraizamento dos indivíduos e das organizações em seus territórios imaginários e espaciais. Esses pontos de enraizamento são justamente os sítios; fornecem áreas de estabilidade aos fenômenos sociais, inclusive aos processos econômicos (ZAOUAL, 2006, p. $35)$.

Por fim, os sítios de pertencimento de Zaoual (2006) são derivados das relações sociais/econômicas, ou seja, culturais de um local; são construções que se formam pelos entrelaçamentos entre os indivíduos.

O trabalho artesanal antecede a organização do trabalho industrial; a organização se dá de diferentes formas. O trabalho artesanal contemporâneo é decorrente do aprofundamento de laços de reciprocidade e de solidariedade que, na atualidade, ultrapassam o ambiente familiar. Segundo Machado (2010), os laços sociais e de reciprocidade podem atuar como facilitadores para finalidades econômicas, em especial quando desenvolvidas em grupo. Apesar do trabalho artesanal ter ênfase no saber-fazer o todo (do produto), esse trabalho não é isolado, mas é entremeado de diversos aspectos relacionais entre pessoas, desde o repasse da tradição, bem como, mais na contemporaneidade, na organização em coletivos para a produção e comercialização

\section{O trabalho artesanal: a comercialização}

Se o trabalho, historicamente, foi desenvolvido para a subsistência do homem, como o trata a economia substantiva, no modelo de organização da produção capitalista, o trabalho objetivava maximizações individuais. Polanyi (2012) demonstra que a subsistência do homem foi alterada a partir do modelo fundamentado na maximização individual, ocorrendo um desenraizamento, tal como Zaoual (2005) questiona a desnaturalização do homem como elemento da natureza.

Polanyi (2012), a partir do seu resgate histórico das sociedades ocidentais, demonstra que na organização da produção industrial ou do trabalho para a produção industrial o homem ou o trabalho humano passa a ser compreendido como mercadoria a compor o produto, ou seja, uma mercadoria desenraizada de conhecimentos para a promoção de sua própria subsistência. Nessas sociedades, o homem promove sua subsistência como mercadoria trocada por salário ou como beneficiário de programas de seguridade dos Estados. Nessas sociedades, as relações sociais são estabelecidas por contratos, com regras escritas que reduzem as liberdades do homem à vida. 
[...] o sustento e a segurança dos indivíduos não são mais garantidos por laços comunitários; suas relações recíprocas e suas necessidades já não são definidas tradicionalmente, por meio de instituições de parentesco, religiosas e políticas. Por isso, todos devem "economizar" e "maximizar", seja seu objetivo aumentar o capital, seja ganhar a vida (POLANYI, 2012, p. 19).

No trabalho artesanal, por não haver o fracionamento do saber-fazer, e ser um produto o que é comercializado, o homem não é concebido como uma mercadoria, tampouco a origem do seu conhecimento é advinda de relações mercantis. A organização do trabalho artesanal permeia relações sociais, distintas das que estruturam as trocas mercantis.

Polanyi (2012) aponta outros princípios que apoiam as decisões de produção de sociedades, mostrando que existem outras maneiras de se produzir em sociedade, ultrapassando a comum noção de maximização individual ou acumulação de capital. A existência de outros princípios que permeiam as relações entre os homens e os meios são decorrentes de outras normas de conduta, ou ainda, de outros laços de confiança ou de solidariedade, o que possibilita a construção ou entendimento de outras economias:

[...] deve reconhecer - se a relevância da definição substantiva, que encara a economia enquanto processo instituído de interação entre o homem e o seu ambiente natural e social, o qual resulta numa contínua oferta de meios materiais para satisfazer as suas necessidades - esta sim com carácter universal - e que constitui a base para o método preconizado por Polanyi: a análise institucional. Ora, a economia pode estar instituída de diferentes formas nas mais variadas sociedades, sendo que Polanyi identifica três padrões fundamentais designados por formas de integração - reciprocidade, redistribuição e troca (mercantil) (MACHADO, 2010, p. 73).

Zaoual (2006, p. 46), a exemplo de Polanyi (2012), também faz referência ao desenvolvimento de outras racionalidades em razão das normas locais:

A racionalidade situada é uma racionalidade das crenças e das ações que se desenrolam, em maior ou menor sintonia, sobre o sítio. Regras e normas desempenham o papel de operadores que ordenam e põem coerência entre o que é normal no sítio e as ações cotidianas dos atores, ou entre o não-dito e o que se faz na prática.

Os diferentes princípios que promovem distintas racionalidades coexistem nas sociedades e se manifestam em formas irregulares de organizações da produção para a subsistência pelas dissemelhantes organizações do trabalho. Nas sociedades ocidentais, as racionalidades forjadas pelo Estado e pelo Mercado, de acordo com Polanyi (2012), estão em constantes disputas acadêmicas e de poder político e econômico, mascarando e/ou inviabilizando o amadurecimento de diferentes 
formas de organização de trabalho, tal como o trabalho artesanal e o trabalho da agricultura familiar no Brasil.

A economia social (CAEIRO, 2008) e a economia solidária (SINGER, 2004) são exemplos de outras economias, em meio ao modelo hegemônico da propriedade privada dos meios de produção e da regulação deste pelo Estado liberal.

O trabalho artesanal, ora inserido no sistema de organização e distribuição capitalista, é, por vez, promotor de outras economias, e muitas vezes denominado de trabalho informal por não deter as proteções sociais do Estado liberal, encontrando resistência à comercialização do seu produto. O produto artesanal não possui escala para comercialização em estabelecimentos comerciais similares aos que comercializam produtos industrializados, seja por alguns produtos serem perecíveis, seja por demandarem muito tempo para confecção, seja pelas dificuldades de deslocamento.

Inúmeros são os fatores que demandam outras formas de organização para a comercialização de produtos artesanais: feiras, programas de compra direta do governo, venda direta, entre outras. Geralmente, organizações de artesãos se organizam em grupos para atender a demanda de quantidade, de deslocamento, de variedade, entre outras.

Observa-se que os espaços de comercialização ou venda direta colocam em contato o criador/produtor e comprador, proporcionando o desenvolvimento de uma racionalidade de proximidade, de construção social; uma racionalidade que ultrapassa as negociações de preços ou da troca de produtos por dinheiro, promovendo relações simétricas entre os indivíduos, assimilando interdependência social, preocupação com o outro, além de valores humanos, ou seja, fomenta relações de reciprocidade (MACHADO, 2010, p. 73).

O trabalho artesanal, baseado no saber-fazer repassado nas gerações pela reciprocidade, também desenvolve produtos que desempenham um papel muito além de suprir as necessidades de subsistência do homem, pois promove princípios de reciprocidade em meio às trocas mercantis.

De acordo com Nierdeli e Radomsky (2016, p. 51), o trabalho artesanal fornece um conjunto de experiências agregadoras para o desenvolvimento humano individual e coletivo, cumprindo uma finalidade de construção do bem-estar mútuo: "a vida das pessoas é a finalidade última, sendo a produção e a prosperidade meros meios para atingi-la”.

\section{Considerações finais}

As literaturas (artigos e trabalhos acadêmicos) culturais (saberes e memória) e econômicas (substantivas) relacionadas ao trabalho artesanal são escassas e quando existentes, são muitas vezes 
superficiais no que tange ao sentido do trabalho nas sociedades. Assim, considera-se que a abordagem realizada neste artigo é relevante; um material que direciona ou clama pelo aprofundamento de futuras investigações.

O saber-fazer, que proporciona a existência do trabalho artesanal, é materialidade e imaterialidade ao mesmo tempo e ao ser repassado como tradição, atua com princípios de reciprocidade e colaboração, tal como os mantém a família, como uma estrutura endogenamente na sociedade brasileira.

O trabalho artesanal não ocupa dimensões isoladas do econômico, social ou do ambiental de onde ocorre; ele se mostra integrador dessas dimensões na dimensão cultural. Uma dimensão que se enfraquece quando as outras que lhe dão suporte são substituídas ou transformadas (muitas dessas decorrentes de avanços tecnológicos dependentes e de imposições de instituições externas), porém, mais sério ainda, são as transformações pela inexistência do sentimento de pertencimento.

No Brasil, os espaços de comercialização de produtos do trabalho artesanal não deixam dúvida quanto à existência da necessidade de incentivo a eles, num contexto de produções desenraizadas de conhecimento situado, valendo assim os esforços ao aprofundamento das pesquisas relacionadas a outras racionalidades ou outras economias que podem apoiar o desenvolvimento territorial, respaldado pela cultura local e pelo sentimento de pertencimento territorial.

Por fim, considera-se relevante à promoção da subsistência do homem e da natureza a disseminação dos conhecimentos de outros princípios que regem outras economias, pois estes subsidiam as tomadas de decisões individuais e coletivas, a exemplo, a ecossocioeconomia.

\section{Referências}

CAEIRO, J. M. C. Economia social: conceitos, fundamentos e tipologia. Katál, Florianópolis, v. 1, n. 11, p. 61-72, jan./jun. 2008.

CASTELLS, M. A sociedade em rede. São Paulo: Paz e Terra, 1999. (Volume 1).

CLAVAL, P. A geografia cultural. 3. Ed. Florianópolis: UFSC, 2007.

DICIONÁRIO MICHAELIS. Disponível em: <https://michaelis.uol.com.br/modernoportugues/busca/portugues-brasileiro/trabalho/>. Acesso em: 09 jul. 2018.

DICIONÁRIO ETIMOLÓGICO. Disponível em:

<https://www.dicionarioetimologico.com.br/trabalho/>. Acesso em: 31 jul. 2017.

HOBSBAWN, E.; RANGER, T. (Orgs.). A invenção das Tradições. Rio de Janeiro: Paz e Terra, 
2008.

Incubadora Tecnológica de Cooperativas Populares de Itajubá - INTECOOP. Cartilha de formação de grupos. Disponível em: 〈http://www.intecoop.unifei.edu.br/cartilha.pdf〉. Acesso em: 31 jul. 2017.

KELLER, P. F. Trabalho artesanal e cooperado: realidades, mudanças e desafios. Revista Sociedade e Cultura, Goiânia, v. 14, n. 1, p. 29-40, 2011.

MACHADO, N. M. C. Karl Polanyi e a Nova Sociologia Económica: notas sobre o conceito de “(dis)embeddedness". Revista Crítica de Ciências Sociais, n. 90, 2010.

NIERDELI, P. A.; RADOMSKY, Guilherme Francisco Waterloo (Orgs.). Introdução às Teorias do Desenvolvimento. Porto Alegre: UFRGS, 2016.

PECQUEUR, B. O desenvolvimento territorial: uma nova abordagem dos processos de desenvolvimento para as economias do sul. Raízes, Campina Grande, v. 1-2, n. 24, p. 10-22, jan./dez., 2005.

PECQUEUR, B.; BENKO, Georges. Os recursos de territórios e os territórios de recursos. Revista Geosul, Florianópolis, v. 16, n. 32, p. 31-50, 2001.

POLANYI, K. A subsistência do homem e ensaios correlatos. Tradução de Vera Ribeiro. Rio de Janeiro: Contraponto, 2012.

SINGER, P. Introdução à Economia Solidária. São Paulo: Fundação Perseu Abramo, 2004

ZAOUAL, H. Nova economia das iniciativas locais: uma introdução ao pensamento pós-global. Rio de Janeiro: DP\&A; COPPE/UFRJ, 2006.

Artigo recebido em 11/04/2018. Aceito para publicação em 22/05/2018. 